\title{
Nanolithography Study Using Scanning Probe Microscope
}

\author{
S. Sadegh Hassani and H. R. Aghabozorg \\ Research Institute of Petroleum Industry \\ Iran
}

\section{Introduction}

Recently, the interest to design useful nanostructures in science and technology has rapidly increased and these technologies will be superior for the fabrication of nanostructures (Iwanaga \& Darling, 2005; Martin et al., 2005; Sadegh Hassani et al., 2010). The patterning of material in this scale is one of the great importances for future lithography in order to attain higher integration density for semiconductor devices (Sadegh Hassani \& Sobat, 2011).

Conventional lithography techniques, i.e., those divided to optical and electron beam lithography are either cost-intensive or unsuitable to handle the large variety of organic and biological systems available in nanotechnology. Hence, the various driving forces have been considered for development of nanofabrication techniques (Geissler \& Xia, 2004; Quate, 1997; Sadegh Hassani \& Sobat, 2011).

Applying of these techniques has started approximately since 1990 and it has given rise to the establishment of different nanolithography methods, which one of the most important method is scanning probe based lithography. An interesting way of performing nanometer pattern is direct scratching of a sample surface mechanically by a probe. The controlled patterning of nanometer scale features with the scanning probe microscope (SPM) is known as scanning probe lithography (SPL) (Irmer et al., 1998). Many reports have been presented about various lithographic methods by this technique (Garcia, 2004; Garcia, 2006). SPL would also be ideal for evaluation of mechanical characteristic of surfaces.

Scanning probe microscopy, such as scanning tunneling microscopy (STM) and atomic force microscopy (AFM), has become a standard technique for obtaining topographical images of surface with atomic resolution (Hyon et al., 1999). In addition, it may be used to study friction force, surface adhesion and modifying a sample surface (Sundararajan \& Bhushan, 2000; Burnham et al., 1991; Aime et al., 1994; Sadegh Hassani \& Ebrahimpoor Ziaie, 2006; Ebrahimpoor Ziaie et al., 2008). Manipulating surfaces, creating atomic assembly, fabricating chemical patterns and characterizing various mechanical properties of materials in nanometer regime are enabled by this technique (Hyon et al., 1999; Sadegh Hassani \& Sobat, 2011; Bouchiat \& Esteve, 1996).

Nanolithography with AFM is also a tool to fabricate nanometer-scale structures with at least one lateral dimension between the size of an individual atom and approximately 100 $\mathrm{nm}$ on silicon or other surfaces (Wilder \& Quate, 1998). This technique is used during the fabrication of leading edge semiconductor integrated circuits (Sugimura \& Nakagiri, 1997) 
or nanoelectromechanical systems (NEMS). This method is not restricted to conductive materials (Fonseca Filho et al., 2004). The advantages of this technique are high resolution and alignment accuracy, which could not be achieved by conventional lithographic techniques (Sheehan \& Whitman, 2002; Martin et al., 2005). Moreover, the AFM nanolithography technique takes advantages of the ability to move a probe over the sample in a controllable way (Samori, 2005). Nanolithography using AFM can be done in various modes (Jones et al., 2006): chemical and molecular patterning (DPN), mechanical patterning by scratching or nanoindentation, local heating, voltage bias application and manipulation of nanostructures. Most popular AFM lithographic techniques are resist film lithography (Li et al., 1997) and lithography by oxidation (Sheglov et al., 2005; Sugimura et al., 1993; Sadegh Hassani et al., 2008a; Dubois \& Bubbendroff, 1999; Avouris et al., 1998; Snow et al., 1999; Lemeshko et al., 2005; Avouris et al., 1997). The atomic force microscope has also become an increasing popular tool for manipulating thin films of many different types of materials. Lithography techniques can be carried out on the film of polymers such as polymethylmethaacrylate (PMMA), chloromethyl phenyltrichlorosilan (CMPTS), polyethylene (PE) and others (Lee et al., 1997; Sadegh Hassani et al., 2008b, Yoshimura et al., 1993; Chen et al., 1999; Huang et al., 2001). This capability can potentially be extended to evaluate nano-scale material response to indentation and would be ideal for evaluation of mechanical characteristic of surfaces (Burnham \& Colton, 1989; Hues et al., 1994; Sadegh Hassani et al., 2008b).

To apply force optimally for making nano scratches, we require to understand the underlying behavior and parameter that control it, a tip which is optimized for applying force under the experimental conditions and scanning techniques which allows one to use these tips and retain desired properties (Yasin et al., 2005; Sadegh Hassani et al., 2008a; 2010). Some factors such as resolution, accuracy of alignment and reproducibility are important in this way. By reducing wear of AFM tip and controlling variables such as applying force, scan speed and environment, it can be systematically calibrated the size of features that is written by AFM tip. So, the reproducibility of issues can be controlled.

In this chapter, it is focused on the use of lithography process to build the desired nanostructures and nanolithography on surface of different substrates by AFM. Creating the scratches on various surfaces by silicon nitride and diamond tips using contact mode is discussed. For scratching, the mechanical action of the tip as a sharp pointed tool in order to produce fine scratches is used (Notargiacomo et al., 1999; Sadegh Hassani et al., 2010). The direct scratching is possible with high precision but low quality results are obtained due to probe wear during lithographic process.

Silicon nitride cantilever tip with average spring constant is used to investigate soft surfaces including poly methyl methacrylate (PMMA) (LG-IH 830) thin film coated on the silicon and glass substrates (Sadegh Hassani et al., 2008a). A diamond cantilever tip with high spring constant is used for hard surfaces including highly-oriented pyrolytic graphite (HOPG) and polyethylene substrate (Sadegh Hassani et al., 2010). Since its hardness is much more than silicon nitride, the direct formation of nanoscratches could easily be achieved.

Effects of applied normal force, time of applying pressure, speed and number of scratching cycles on the geometry and depth of scratches are studied. This study shows that there is a critical tip force to remove material from various surfaces (Sadegh Hassani et al., 2008a; 2008b; 2010). 


\section{Force lithography}

An interesting way of performing nanometer pattern is force lithography which based on direct mechanical impact produced by a sharp probe on the sample surface (Lyuksyutov et al., 2003; Park et al., 2000; Sadegh Hassani et al., 2008a). The probe tip pressure on the surface is sufficient to cause plastic deformation of the substrate surface. This type of modification has been used in nanoelectronics, nanotechnology, material science, etc. It enables the fabrication of electronic components with active areas of nanometer scale, super dense information recording and study of mechanical properties of material.

In force lithography no bias voltage is required to produce nanostructures. The nanostructure formation normally occurs as a result of AFM tip motion above the polymer surface with set point magnitude constraining the tip to come closer to the surface (Lyuksyutov et al., 2004; Sadegh Hassani et al., 2008a; 2008b; 2010). In order to apply sufficient normal load to reach plastic deformation of surface, a three-side pyramidal single crystalline diamond tip or another tip with high spring constant is used and pressed against a desired surface (Santinacci et al., 2003; Sadegh Hassani et al., 2010). Much higher forces are achieved by accordingly increasing the applied voltage to piezo-scanner. By scanning the sample in the $X$ or $Y$ direction at various conditions (such as different scanning velocity and number of cycles) grooves are created. However, the protrusions along the edges are formed, which indicates clearly stress deformation during the scratching process (Santinacci et al., 2005).

It is shown that by applying a little force (several $\mu \mathrm{N}$ ), removing an amount of material from a metal or polymer film is possible (Bruckl et al., 1997).

Use of cantilevers with high spring constant could apply the desired amount of force without large bending. When tip move toward the substrate or reverse direction, up or down bending of cantilever occurs, respectively. Since an angle of about $10^{\circ}$ is typically set between the cantilever and the substrate (see Fig.1. b), this bending influence the tipsubstrate interaction, so the geometry and size of scratches are affected in this way. However, increase of applied force cause cumulating of material along or at the end of the grooves. This deformity is occurred because of cantilever bending at the start point of moving tip through the surface. In this way cantilever reach the desired force to create scratch. (Notargiacomo et al., 1999; Sadegh Hassani \& Sobat, 2011).

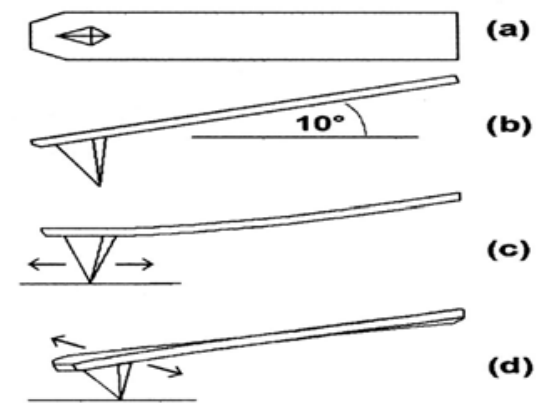

Fig. 1. Typical silicon cantilever with pyramidal tip: (a) upper view; (b) lateral view showing the $10^{\circ}$ angle formed with the substrate surface; (c) cantilever bending and (d) torsion

(Notargiacomo et al., 1999). 
Resolution will be major challenge in lithographic fabrication and the limiting factor for resolution is the tip quality. Sharp silicon tips deliver brilliant and reproducible results. To even further achieve the fine lithographic structure, electron beam deposited tips (EBD tips) can be additionally sharpened in oxygen plasma (Wendel et al., 1995).

Wearing of probe led to low-quality results and reduced the repeatability of produced scratches. Indeed, by using the same tip at another experiment, the sample surface could experience two completely different values of pressure, because the amount of produced pressure depends on the shape of tip (Hu et al., 1998). To decrease wearing of probe, a soft resist polymer film (usually PMMA film) is coated on the surface. On the other hand, the roughness of surface is very important to take high quality scratches. Observations show that surface roughness is strongly influenced by its thickness as while; the surface roughness increases with the increase of the thickness. So, to perform the lithography process, the smoothest surface has to be chosen (Yasin et al., 2005; Fonseca et al., 2004).

Studies show that in the case of AFM, the possibility of directly machining a surface has been explored in two ways, i.e. by either using a static approach in which the microscope is operated in conventional contact mode (Magno \& Bennett, 1997; Sumomogi et al., 1995) or using a dynamic approach in which the microscope is operated in the tapping mode (Heyde et al., 2001; Davis et al., 2003). Usually the lithography developed using both static and dynamic approaches are employed to pattern a resist layer, subsequently the patterned layer is used as an etch mark. Both techniques are giving lithography resolution of the order of tens of nanometer (Wendel et al., 1994; Quate, 1997).

An advantage of the vibration in the tapping mode is that very small lateral forces stress the tips, resulting in very slow tip degradation (Wendel et al., 1996).

\section{Force curve}

In lithographic experiments, it is often critical to know the tip pressure on the desired sample. To estimate the pressure corresponding to a specified level of the probe impact, the force created by the probe has to be determined. It can be calculated from force spectroscopy data.

The normal force between tip and sample is estimated from cantilever deflection (nA) curve plotted against Z-displacement of the cantilever and converting this curve to Force-Distance curve (Vanlandingham, 1997; Yeung et al., 2004; Carallini et al., 2003; Santinacci et al., 2005; Sadegh Hassani et al., 2008a; Argento \& French, 1996). To take the force curve, to avoid punching surface, it is essential that the sample has a rigid surface such as silicon or polycrystalline substrate. By performing spectroscopy in a point, force curve is obtained.

The conversion factor for converting $\mathrm{nA}$ to $\mathrm{nm}$ was obtained from the slope of the linear portion of the deflection-distance curve. There was also one conversion needed for the Xaxis values. The change in piezo height, which has been used for the distance between the tip and the sample, was corrected for the deflection of the cantilever by subtracting the cantilever deflection from the piezo height.

On the other hand, there are two measurements required to convert photo detector signal into a quantitative value of force. The first stage is to calibrate the distance that the cantilever actually deflects for a certain measured changes in photo detector voltage. This value depends on type of cantilever and the optical path of the AFM detection laser. When every cantilever is mounted in the instrument, this value will be slightly different. Once the deflection of cantilever is known as a distance $Z$, the spring constant $k$, is needed to convert 
this value into a force $\mathrm{F}$, using Hook's law $(\mathrm{F}=\mathrm{k} \times \Delta \mathrm{Z})$ (Heimberg \& Zandbergen, 2004; Ebrahimpoor Ziaie et al., 2005; Carpick \& Salmern, 1997; Sadegh Hassani \& Ebrahimpoor Ziaie, 2006).

\section{Nanolithography on various substrates}

In some reported experiments, a commercial scanning probe microscope (Solver P47H, NTMDT Company), operated in AFM contact and noncontact modes, equipped with (NSG11) and (DCP20) cantilevers were used to perform the lithography of desired surfaces (Sadegh Hassani et al., 2008a; 2008b; 2010). The NSG11 cantilever made of silicon nitride had a rectangular shape, and its length, width and thickness were $100 \pm 15 \mu \mathrm{m}, 35 \pm 3 \mu \mathrm{m}$ and 1.7 $2.3 \mu \mathrm{m}$, respectively. Its normal bending constant measured by supplier was $11.5 \mathrm{nN} / \mathrm{nm}$. Another cantilever which was used in this process was DCP20 Cantilever made of diamond with the length, width and thickness of $90 \pm 5 \mu \mathrm{m}, 60 \pm 3 \mu \mathrm{m}$ and 1.7-2.3 $\mu \mathrm{m}$, respectively. The normal bending constant measured by supplier was $48 \mathrm{nN} / \mathrm{nm}$.

These two types of cantilever were selected to reach deformation of different types of surfaces and also for obtaining good images of scratches. These experiments were designed to fabricate scratches on the various surfaces with the different rigidity.

The lithography process was executed with the use of lithography menu supported by the microscope software. The AFM tip was brought into contact with the sample surface using the smallest force possible to minimize any undesired surface modification. An image of surface was prepared in order to choose a suitable surface free of defects for lithography; then the nanolithography process was executed under various specific and controlled conditions to analyze the effect of lithography important factors on the shape of scratches.

For studying force effect, the force was increased by applying a higher voltage to the piezoscanner in order to reach the cantilever deflection $(\Delta \mathrm{Z})$ corresponding to the force $(\mathrm{F})$ range where plastic deformation of polymeric surface occurred. (Santinacci et al., 2003; Notargiacomo et al., 1999; Sadegh Hassani et al., 2008 b). Scratches were made in Y direction on various substrates in different conditions (Sadegh Hassani et al., 2008a; 2008b; 2010), so in this way the influences of applied normal force, scanning velocity, time of applying pressure and number of scratching cycles were investigated. Finally surface was scanned by atomic force microscope in non-contact mode to observe and evaluate the shape and depths of scratches. If the contact mode had been chosen to image the scratches, the surface of substrates would have probably been damaged.

\subsection{Nanolithography on PMMA thin films}

Sadegh Hassani et al. (2008a; 2008b; 2010) reported lithography performance on PMMA thin films. In this regard, soft thin films of PMMA polymer on the silicon and glass substrates were prepared. For making PMMA (LG-IH830) thin film on silicon and glass substrates, these substrates were washed and sonicated in acetone/ethanol (50-50\% vol.) for 15 minutes at room temperature. Then a very small amount of diluted $\mathrm{PMMA} / \mathrm{CHCl}_{3}$ solution was coated over the silicon and glass surfaces using spin coater with $6000 \mathrm{rpm}$ for 30 seconds. The coated substrates were dried in an oven at $130{ }^{\circ} \mathrm{C}$ for 30 minutes. The thickness of these coated layers was $\sim 150 \mathrm{~nm}$, measured by atomic force microscope. 
In order to choose suitable area for nanolithography process, the topography images and the roughness of the surfaces of PMMA thin films were investigated with the AFM (Sadegh Hassani et al., 2008a). It was reported (Notargiacomo et al., 1999) that "a high value of the surface roughness could produce unwanted features and inhomogeneous results during patterning". At the first step, it was necessary to evaluate the substrate surface after cleaning. In Figure 2 the evolution of the topography images and profiles of the silicon surface after cleaning and PMMA thin films are presented. It is seen that the roughness of PMMA thin film is low and its surface profile is appropriate for lithography. An accurate study was performed on the samples in order to find the optimum patterning conditions for the PMMA film.

(a)

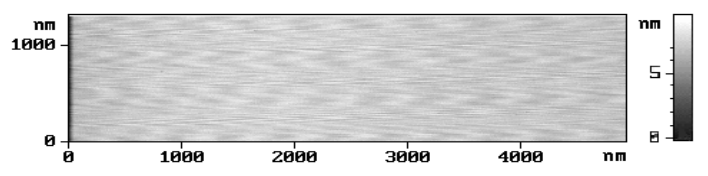

(c)

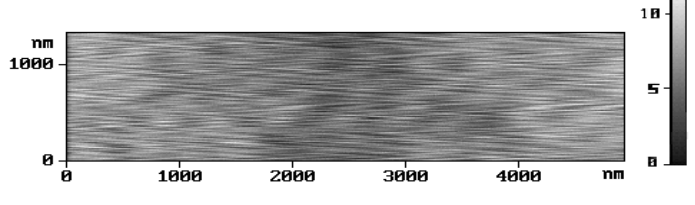

(b)

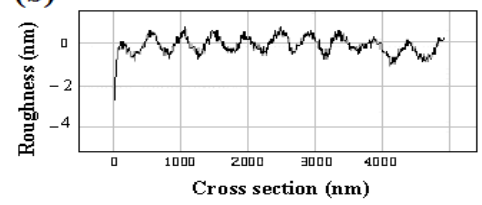

(d)

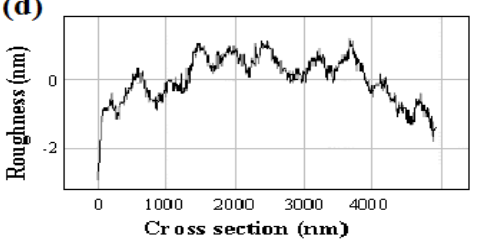

Fig. 2. The evolution of the topography images and profiles of ( $\&$ \& b) silicon surface after cleaning and (c \& d) PMMA thin film (Sadegh Hassani et al., 2008a).

For PMMA coated on silicon substrate, scratches were performed using the NSG 11 tip. The main factor in pattern formation was the magnitude of the force applied to the sample. The influence of the applied normal force on the scratches created on the PMMA film coated the silicon substrate had been investigated. In Figure 3 (a-e) some of surface profiles of nanoscratches are presented, which are formed with the constant scanning velocity of 140 $\mathrm{nm} / \mathrm{s}$, number of scratching cycle of 10 within $25 \mathrm{~ms}$ at various forces $(2350,2700,3050$, 3400 , and $3510 \mathrm{nN}$ ).

These profiles indicate that the increase of applied normal force, leads to the deeper scratches. The scratches are V-shape; however protrusions are visible along some of the scratches indicating the presence of permanent deformation. It was found that the optimum value for applied normal force was about $3050 \mathrm{nN}$. The scratch made by this force is shown in Figure 4. In Figure 5, the scratch depths are plotted as a function of the applied normal force. As expected, the scratch size increases with increasing the force load. The depth varies from 4 to $32 \mathrm{~nm}$ by increasing force load from 1300 to $3510 \mathrm{nN}$. However, Notargiacomo et al. claimed (1999) that as the applied force increases, curved cuts ("tails") become visible at the ends of the lines. It has to be mentioned that due to the convolution effect of the tip and 
substrate topography, the scratch depth may appear smaller by AFM imaging than their actual size (Sadegh Hassani et al., 2008a).
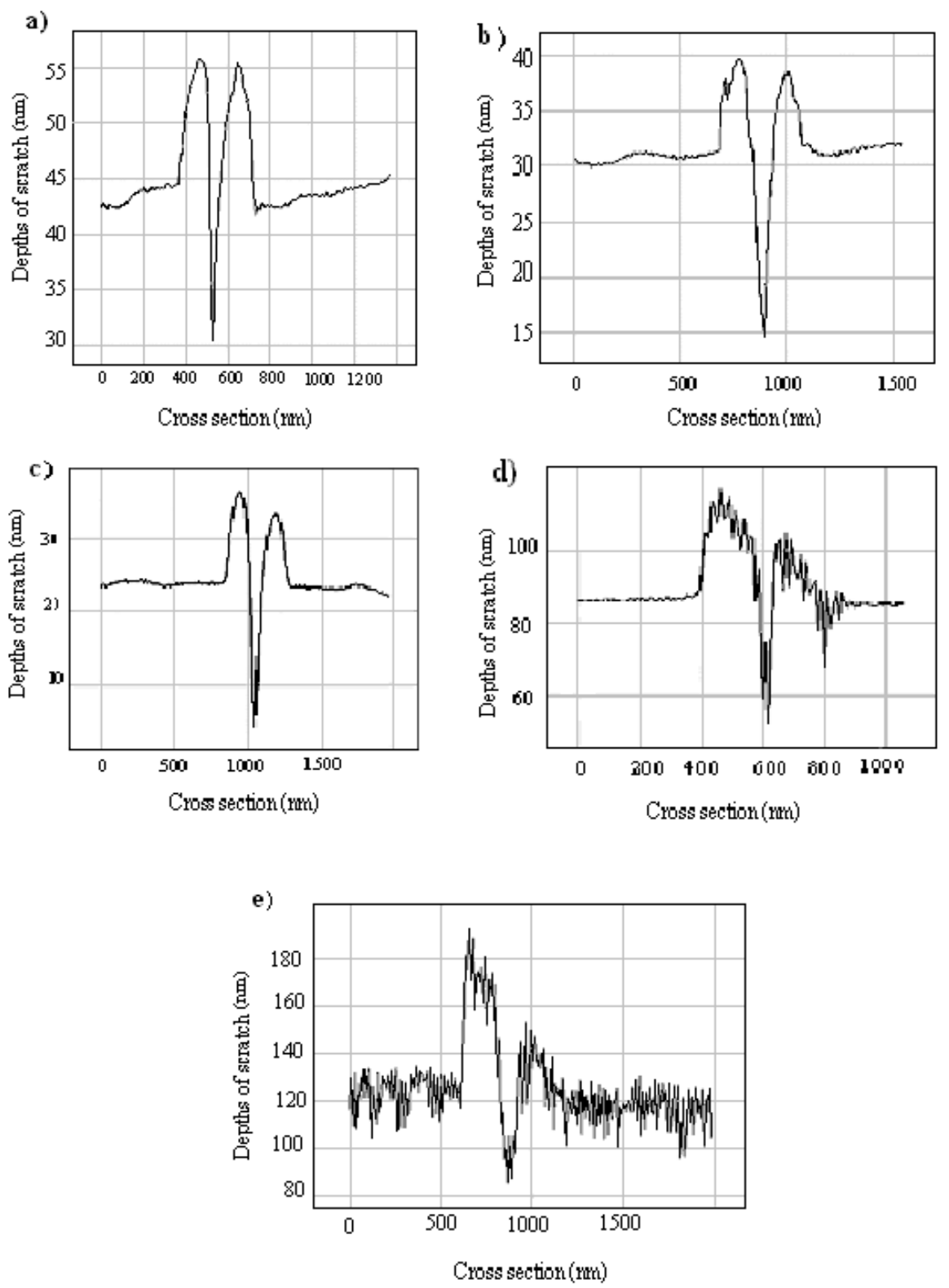

Fig. 3. (a-e) Surface profiles for scratched PMMA film (Sadegh Hassani et al., 2008a) (N=10 cycles, $\mathrm{T}=25 \mathrm{~ms}, \mathrm{~V}=140 \mathrm{~nm} / \mathrm{s}$ and $\mathrm{F}$ is equal to (a) $2350 \mathrm{nN}$, (b) $2700 \mathrm{nN}$, (c) $3050 \mathrm{nN}$, (d) $3400 \mathrm{nN}$ and (e) $3510 \mathrm{nN}$ ). 
(a)

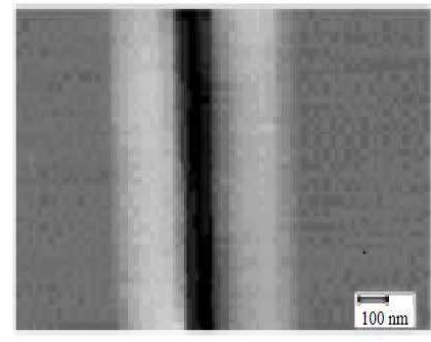

(b)

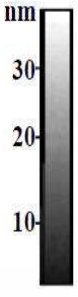

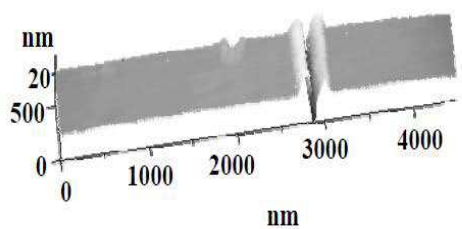

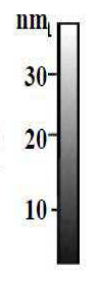

Fig. 4. Topography images of the scratch performed on the PMMA / silicon (Sadegh Hassani et al., 2008a; 2008b; 2010) at $\mathrm{N}=10$ cycles, $\mathrm{T}=25 \mathrm{~ms}, \mathrm{~V}=140 \mathrm{~nm} / \mathrm{s}$ and $\mathrm{F}=3050 \mathrm{nN}$. (a) Two dimensional image and (b) Three dimensional image

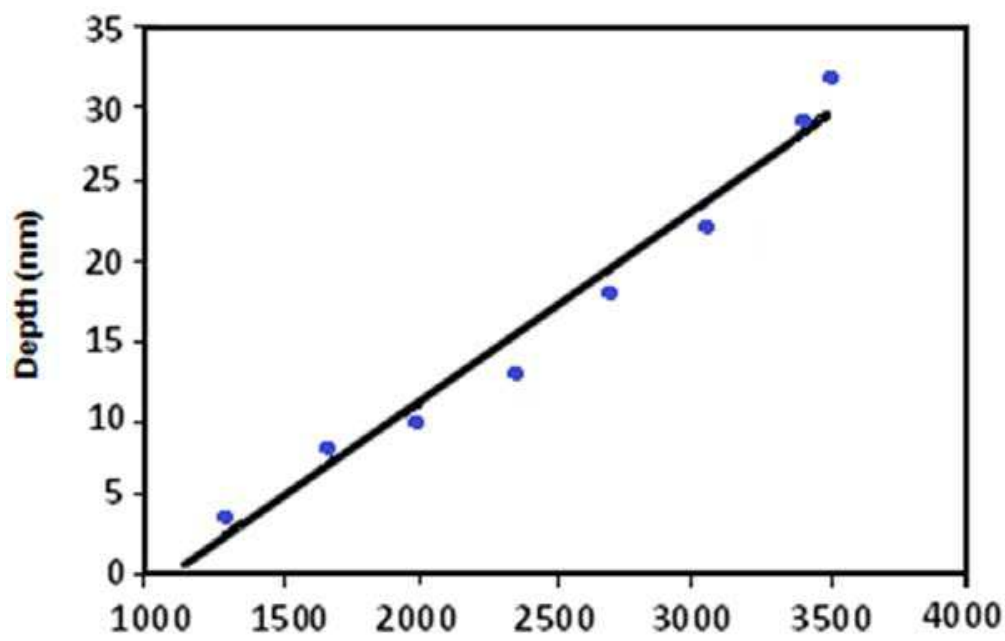

Force (nN)

Fig. 5. Dependence of the scratch depth, created on PMMA/silicon, to the applied normal force (Sadegh Hassani et al., 2008a; 2008b; 2010). (The time of applying pressure, number of scratching cycle and scanning velocity are $25 \mathrm{~ms}, 10$ and $140 \mathrm{~nm} / \mathrm{s}$, respectively.)

For PMMA coated glass substrate, scratches were performed with exerting various normal forces using NSG 11 tip. In Figure 6, the groove depths are plotted as a function of the applied normal force for PMMA on glass substrate. The most uniform scratches were achieved by applying 3,000 $\mathrm{nN}$ force load, while scanning velocity, number of scratching cycle and time of applying pressure were $1400 \AA / \mathrm{s}, 10$ and $25 \mathrm{~ms}$, respectively. Topography image of this scratch is shown in Figure 7. The uniformity of scratches on PMMA coated on silicon and glass is comparable. However, the depth of scratch on the PMMA/glass at the same conditions is more than that of on the PMMA/silicon. 


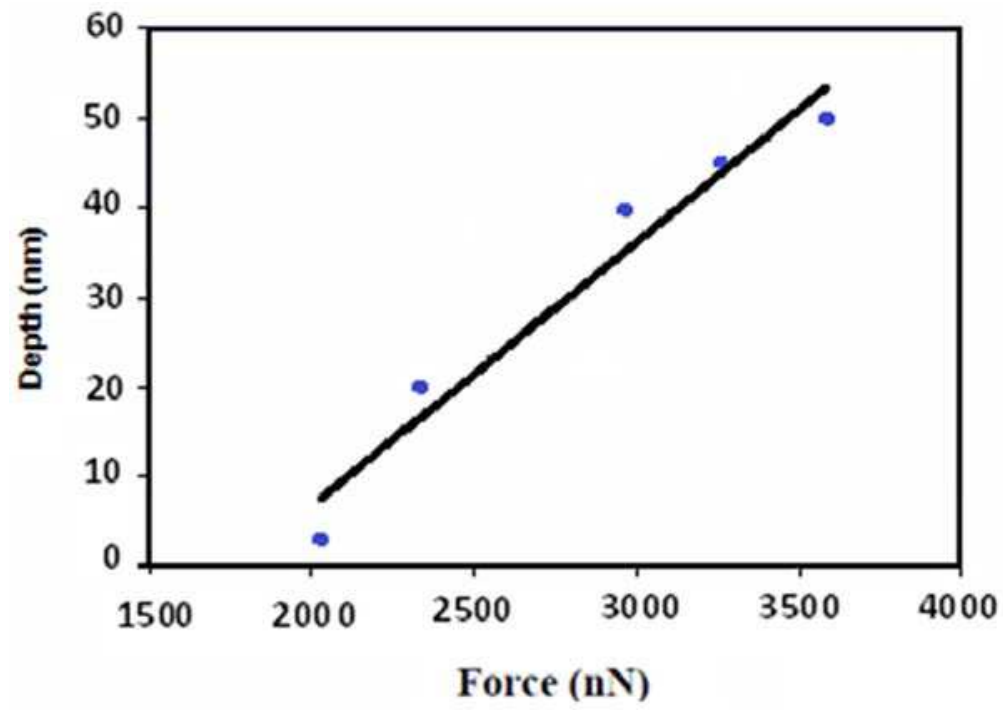

Fig. 6. Dependence of scratches depth, created on PMMA/glass (Sadegh Hassani et al., 2010), with the applied normal force while scanning velocity, number of scratching cycle and time of applying pressure were $140 \mathrm{~nm} / \mathrm{s}, 10$ and $25 \mathrm{~ms}$, respectively.
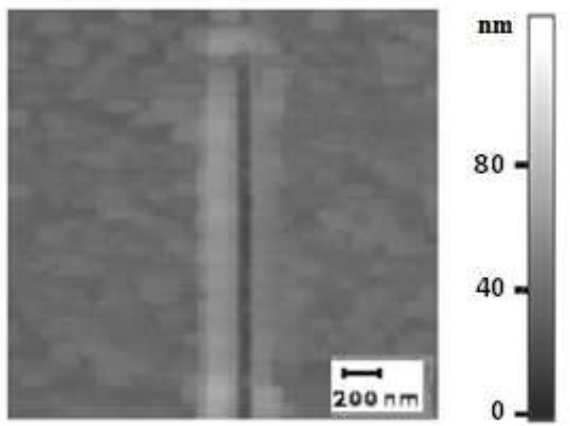

Fig. 7. Topography image of the scratch created on PMMA/glass (Sadegh Hassani et al., 2010), while the applied normal force, scanning velocity, number of scratching cycle and time of applying pressure were $3000 \mathrm{nN}, 140 \mathrm{~nm} / \mathrm{s}, 10$ and $25 \mathrm{~ms}$, respectively.

The influence of the number of scratching cycles was also investigated by scratching experiments. In Figure 8 dependence of the scratch depth to the number of cycles $(N=1,5,10$, $15,20,25$, and 30) in a constant applied normal force of $2350 \mathrm{nN}$, scanning velocity of $140 \mathrm{~nm} / \mathrm{s}$ in $25 \mathrm{~ms}$ is presented. This figure shows that the depth varies from 4 to $30 \mathrm{~nm}$ by increasing the number of cycles. As expected, the depths of scratches increase with $\mathrm{N}$ linearly. This linear relationship between depth and number of cycles confirms layer-by-layer removal mechanism (Sadegh Hassani et al., 2008a). This result is in agreement with that of obtained by Santinacci and coworkers (2003) for performing nanolithography on p-Si (100) substrate. 


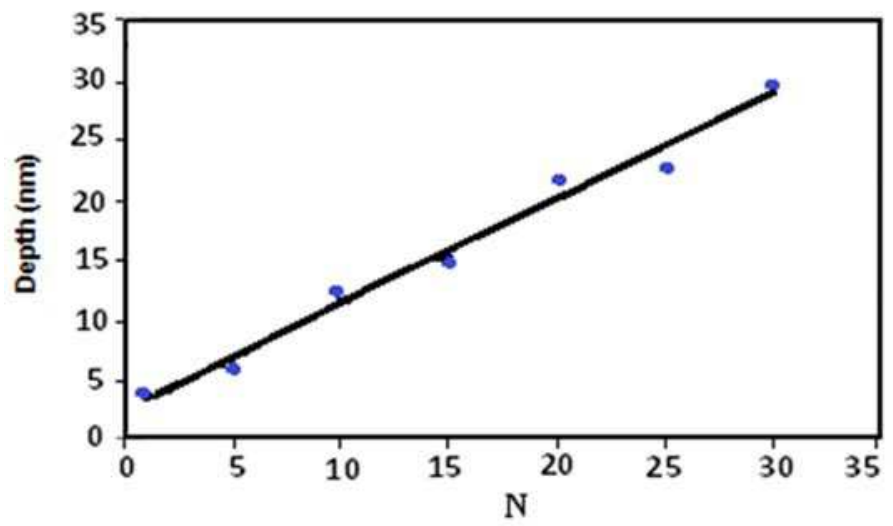

Fig. 8. Dependence of scratch depth created on PMMA/Si to the number of cycles (Sadegh Hassani et al., 2008a; 2008b) (The applied normal force, scanning velocity and time of applying pressure are $2350 \mathrm{nN}, 140 \mathrm{~nm} / \mathrm{s}$, and $25 \mathrm{~ms}$, respectively.)

The influence of the scanning velocity on the lithography pattern, taken at a normal force of $2350 \mathrm{nN}$ is presented in Figure 9. As it is shown in this figure, the depth varies from 24 to 8 $\mathrm{nm}$ by decreasing scanning velocity from 140 to $540 \mathrm{~nm} / \mathrm{s}$. It is observed that the increase of the scanning velocity induces a decrease in the scratch depth. Thus, slower scans seem to generate higher pressure and as a result deeper scratch pattern are obtained. However, it could not be determined whether the depth decreases linearly or exponentially with the increase of the scanning velocity (see Fig. 9). To analyze the time effect, nanoindentations are performed on the PMMA surface. The indentation depth created on PMMA/Si depth as a function of time of applying pressure using constant force is presented in Figure 10. It can be seen that by increasing the time of applying pressure, indentation depth is increased. In the other words, the plastic deformation on the PMMA film is time dependent. In this case, to accumulate the tip-induced stress, dilation changes such as defects created or absorbed near the vicinity of the deformed region on the surface occur. This effect leads to an additional plastic deformation of the film.

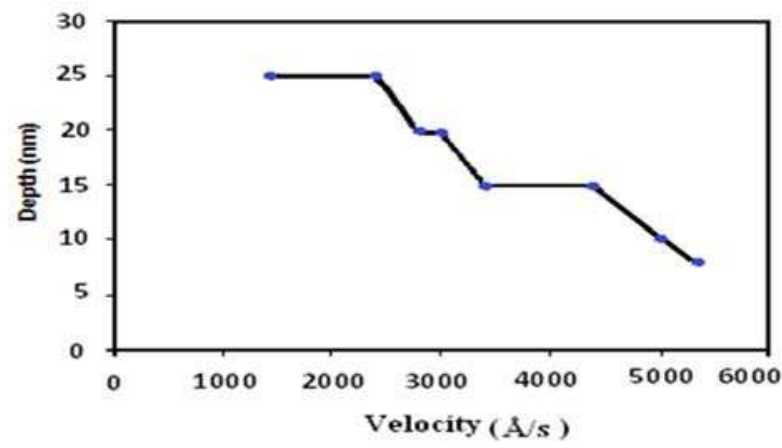

Fig. 9. The influence of the scanning velocity on the depth of the lithographed pattern created on PMMA/Si (Sadegh Hassani et al., 2008a) (The applied normal force, time of applying pressure and number of cycle are $3125 \mathrm{nN}, 25 \mathrm{~ms}$ and 10, respectively.) 


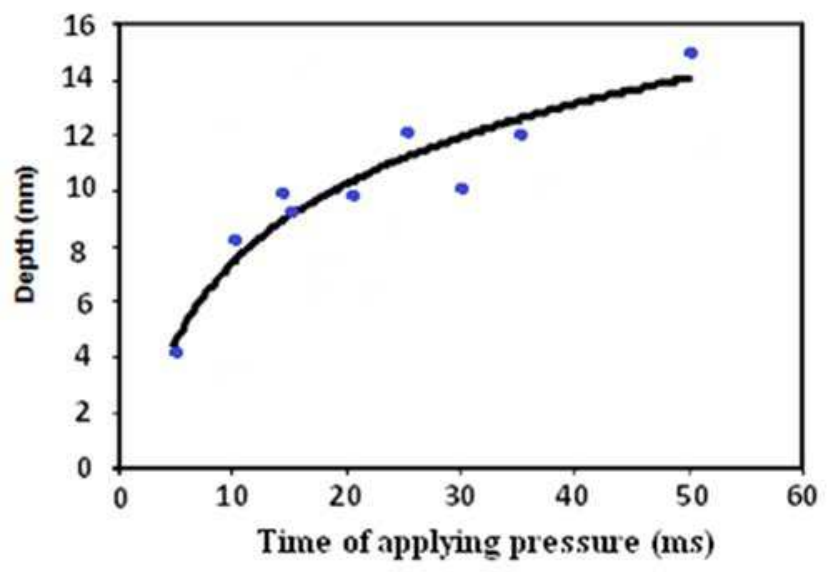

Fig. 10. The indentation depth created on PMMA/Si as a function of the time of applying pressure (Sadegh Hassani et al., 2008a; 2008b) (The applied normal force, scanning velocity and number of cycle are $2350 \mathrm{nN}, 140 \mathrm{~nm} / \mathrm{s}$ and 10, respectively.)

\subsection{Nanolithography on polyethylene substrate}

This experiment was performed on the polyethylene (PE) substrate (Sadegh Hassani et al., 2008b; 2010). Polyethylene surface was cleaned by washing and sonicating in acetone-ethanol (50-50\%Vol.) for 15 minutes at room temperature. This substrate was more inflexible than PMMA thin layer, so performing any modification over PE needed more rigid cantilever tip. The results verified this comment. Scratches were just made by maximum amount of force load, which was equal to $4 \mu \mathrm{N}$ for NSG11 cantilever tip that was the threshold of force for modifying the PE substrate. The investigation of force effect on the PE substrate was continued by DCP20 cantilever with diamond tip. The force load created by this tip was sufficient to make modification on the PE substrate because of higher spring constant.

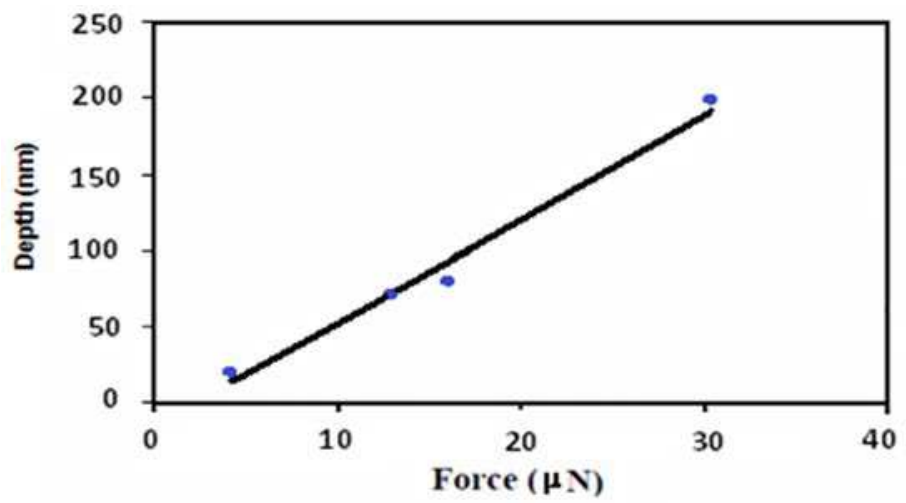

Fig. 11. Dependence of scratches depth with the applied normal force on the PE substrate (Sadegh Hassani et al., 2008b; 2010), while scanning velocity, number of scratching cycle and time of applying pressure are $140 \mathrm{~nm} / \mathrm{s}, 20$ and $50 \mathrm{~ms}$, respectively. 
A topography image of nanoscratche made on the PE showed that the best quality of scratch was obtained by applying of a $4 \mu \mathrm{N}$ force load. The obtained results showed that the uniformity of the scratches reduced by increasing the force load. Accumulation the vicinity of scratches was occurred, because increasing the applied force induced additional plastic deformation. Figure 11 shows the linear increase of scratches depth on the PE substrate as a function of applied normal force. Meanwhile, increase of applied force caused cumulating of material at the start and end point of the grooves. This deformity was occurred because of cantilever bending at the start point of moving tip through the surface (Notargiacomo et al., 1999; Sadegh Hassani et al., 2088b).

In Figures 12 and 13, the indentation depths are plotted as a function of the time of applying pressure and number of cycles for PE substrate, respectively. Figure 12 shows that the dependence of depth to time is not quite linear. This result was also reported by Santinacci et al. (2005). Figure 13 shows the linear increase of scratches depth with number of cycles, as expected (Santinacci et al., 2003; Santinacci et al., 2005; Sundararajan \& Bhushan, 1998).

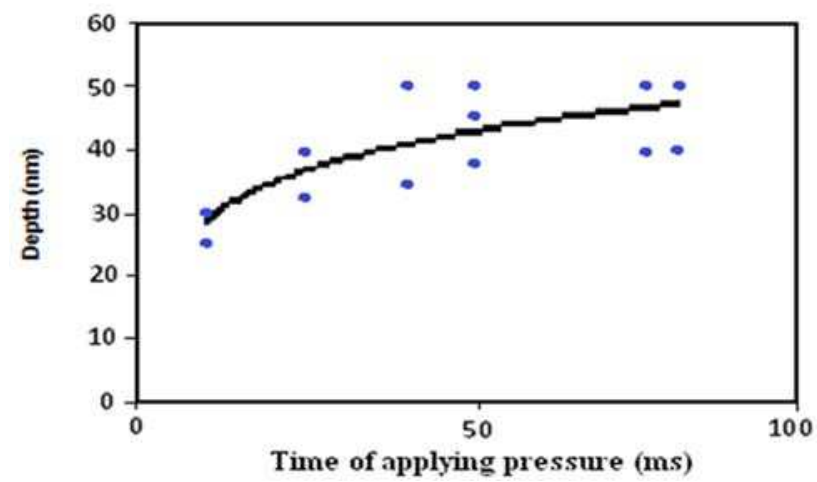

Fig. 12. Indentation depth dependence to time of applying pressure for PE substrate (Sadegh Hassani et al., 2008b), while applied normal force, scanning velocity and number of scratching cycle are $4 \mu \mathrm{N}, 140 \mathrm{~nm} / \mathrm{s}, 10$, respectively.

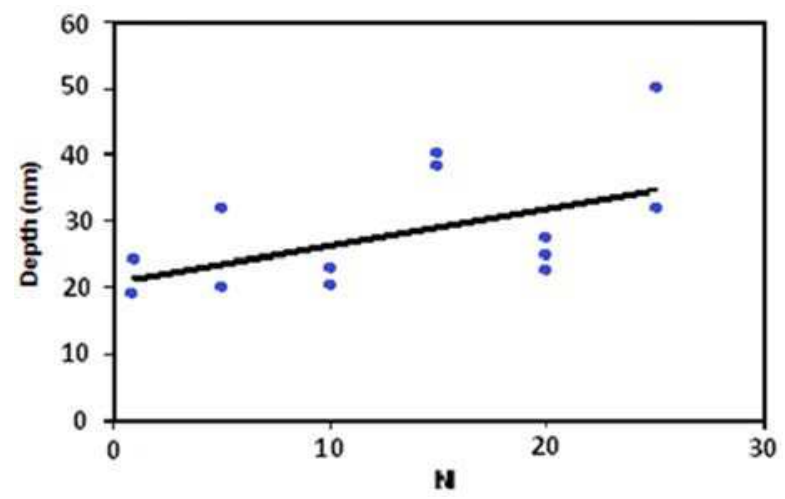

Fig. 13. Indentation depth dependence to number of scratching cycle for PE substrate (Sadegh Hassani et al., 2008b), while applied normal force, scanning velocity and time of applying pressure are $4 \mu \mathrm{N}, 140 \mathrm{~nm} / \mathrm{s}, 25 \mathrm{~ms}$, respectively. 
According to Figures 12 and 13, repeatability of results for PE substrate is less than PMMA layer. It refers to roughness and flexibility of PMMA thin film. In the other words, making scratch over very uniform and flexible PMMA thin layer is much more successful than PE substrate.

\subsection{Nanolithography on HOPG}

This experiment was performed on the HOPG substrate as a completely hard surface and by exerting applied normal force ranging from 5.5 to $50.5 \mu \mathrm{N}$ (Sadegh Hassani et al., 2010). Moreover, in comparison with PMMA thin films and polyethylene substrate, the scanning velocity for performing nanolithography on HOPG surface had to be increased which would led to wearing tip very fast. However, the time of applying pressure on HOPG was much less than those applied on PMMA thin films and polyethylene substrate. Hence, after some trial experiments, $10000 \mathrm{~nm}$ / s was chosen for scanning velocity on HOPG substrate at $1 \mathrm{~ms}$. HOPG surface was cleaned using double-sided tape and removing one layer of it. The results of this experiment are obtained by DCP20 cantilever and are presented in Figure 14. Because HOPG surface was very uniform with very low roughness, shape of made scratches were completely V-form. Topography image and cross section of one of the scratches performed on the HOPG is shown in Figure 15. Meanwhile, increase of applied normal force caused cumulating of material at the start and end point of the grooves. This deformity occurred because of cantilever bending at the start point of moving tip through the surface (Wendel et al., 1996).

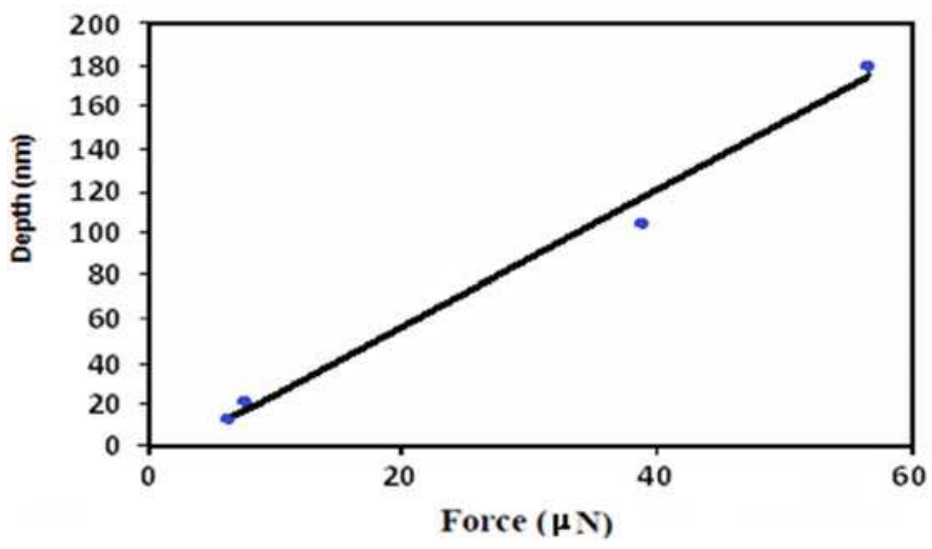

Fig. 14. Dependence of scratches depth to the applied normal force executed by DCP20 cantilever on the HOPG (Sadegh Hassani et al., 2010) substrate, while scanning velocity, number of scratching cycle and time of applying pressure are $10000 \mathrm{~nm} / \mathrm{s}, 1$ and $1 \mathrm{~ms}$, respectively. 

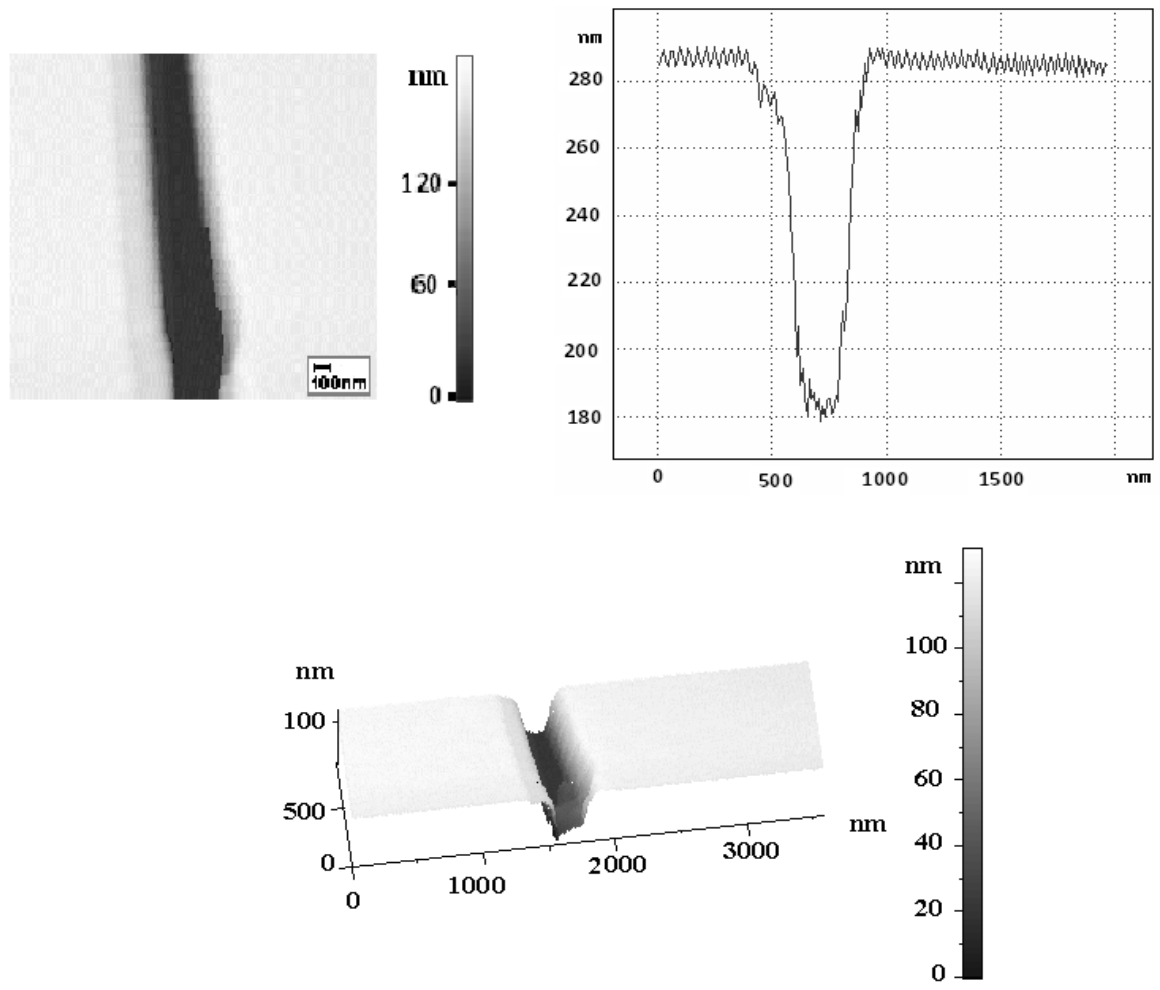

Fig. 15. Two and three-dimensional topography images and cross-section of one of the scratches performed on the HOPG (Sadegh Hassani et al., 2010), while scanning velocity, number of scratching cycle, time of applying pressure and applied normal force are 10000 $\mathrm{nm} / \mathrm{s}, 1,1 \mathrm{~ms}$ and $50.4 \mu \mathrm{N}$, respectively.

\section{Conclusion}

This chapter is focused on the study of the Scanning Probe Lithography in a controlled way on various substrates. The load force produced by silicon nitride (NSG11) tip with average spring constant is sufficient to deform and make scratch on the PMMA thin film. The analysis of the roughness of the surface shows that the concept using a thin insulting film of PMMA on silicon and glass surfaces as a scratching mask can be successfully performed for nanopatterning. Drawing patterns are being controlled by the necessary parameters such as normal force, scanning velocity, time of applying pressure and number of scratching cycle. It is shown that the depth of the lithography mark increases linearly with the increase of the applied normal force. The uniformity of scratches on the PMMA coated on silicon and glass is comparable.

The load force applied by NSG11 tip is not sufficient to exert scratch on the hard surface and is disabled to perform any changes, so diamond tip with much higher spring constant is 
required. It must be mentioned that the minimum necessary force to modify the PE surface is about $4 \mu \mathrm{N}$ that can be achieved by NSG11 tip and with maximum force load. Therefore, for investigation of the effect of higher forces, DCP20 tip is used for PE substrate. The experimental results show that depth of the lithography pattern increased with the increase of the applied normal force with a linear trend for all of the applied substrates. The increase of applied normal force caused accumulating of material at the start and end point of the grooves. This deformity occurred because of cantilever bending at the start point of the tip moving through the surface.

It is presented that the increase of the scanning velocity induces a decrease in the scratch depth. Thus, slower scans seem to generate higher pressure and as a result, deeper scratch pattern are obtained. However, it could not be determined whether the depth decreases linearly or exponentially with the increase of the scanning velocity.

The increase of the lithography depth with the loading time suggests that the plastic deformation on PMMA layer is time dependent. However, the results show that the dependence of depth to the loading time is not quite linear. By the tip-induced stress, dilation changes such as defects created or absorbed near the vicinity of the deformed region on the surface might occur, which would lead to an additional plastic deformation of the film.

It is shown that the depth of the lithography mark increases with the increase of the number of scratching cycle. The depths of scratches increase linearly with the number of scratching cycle.

Finally, due to the convolution effect of the tip and substrate topography, the scratch depth may appear smaller by AFM imaging than their actual size.

\section{References}

Aime, J. P.; Elkaakour, Z.; Odin, C.; Bouhacina, T.; Michel, D.; Curely, J. \& Dautant, A. (1994). Comments on the use of the force mode in atomic force microscopy for polymer films. Journal of Applied Physics, 76, 754-762.

Argento, C. \& French, R.H. (1996). Parametric tip model and force-distance relation for Hamaker constant determination from aromic force microscopy. J. Appl. Phys.,80 (11) 6081-6090.

Avouris, Ph.; Martel, R.; Hertel, T. \& Sandstrom, R. (1998). AFM tip induced and current local oxidation of silicon and metals. Appl. Phys. A 66, S659-S667.

Avouris, Ph.; Hertel, T. \& Martel, R. (1998). Atomic force microscope tip- induced local oxidation of silicon: kinetics, mechanism and nanofabrication. Appl. Phis. Lett. 71(2) 285-287.

Bouchiat, V. \& Esteve, D. (1996). Lift-off lithography using an atomic force microscope, Appl. Phys. Lett ,69(20) 3098-3100.

Bruckl, H.; Rank, R.; Vinzelberg, H.; Monch, I.; Kretz, L. \& Reiss, G. (1997). Observation of coulomb-blockade effects in AFM-machined tunnel junctions. Surf. Interface Anal. 25, 611-613.

Burnham, N. A. \& Colton, R.J. (1989). Measuring the nanomechanical properties and surface forces of materials using an atomic force microscope. Journal of Vacuum Science Technology, A7, Issue 4, 2906-2913.

Burnham, N. A.; Colton, R. J. \& Pollock, H. M.(1991). Interpretation issues in force microscopy. Journal of Vacuum Science E Technology A: Vacuum, Surfaces, and Films, Vol.9, Issue 4, 2548-2556. 
Carallini, M.; Biscarini, F.; Leon. S.; Zerbetto, F.; Bottari, G. \& Leigh, D.A. (2003). Information Storage using Supramolecular Surface Patterns. Science 299, 531.

Carpick, R. W. \& Salmern, M. (1997). Scratching the surface: Fundamental investigations of tribology with atomic force. Chem. Rev. 97, 1163-1194.

Chen, J.; Read, M. A.; Raweltt, A. M. \& Tour, J. M. (1999). Large on- off ratios negative differential resistance in a molecular electronic device. Science, 286, 1550-1552.

Davis, Z. J.; Abadal, G.; Hansen, O.; Borise, X.; Barniol, N.; Perez-Murano, F. \& Boisen, A. (2003). AFM lithography of aluminum for fabrication of nanomechanical systems. Ultramicroscopy $97,467-472$.

Dubois, E. \& Bubbendroff, J. L. (1999).Nanometer sacle lithography on silicon, titanium and PMMA resist using scanning probe microscopy. Solid-state Electronics, 43, 10851089.

Dienwiebel, M.; Verhoeven, G. S.; Pradeep, N.; Frenken, J.W.; Heimberg, J. A. \& Zandbergen, H. W.,(2004). Superlubricity of graphite. Phys. Rev. Lett., 92(12), (126101-1)-(126101-4).

Ebrahimpoor Ziaie, E.; Rachtchian, D. \& Sadegh Hassani, S. (2008). Atomic force microscopy as a tool for comparing lubrication behavior of lubricants. material science: An Indian journal, 4(2), 111-115.

Ebrahimpoor Ziaie, E.; rachtchian, D. \& Sadegh Hassani, S. (2005). Atomic Force Microscopy as a tool for comparing lubrication behavior of lubricants. IV international conference on tribochemistry, 3-5 october, Poland.

Fonseca Filho, H. D.; Mauricio, M. H. P.; Ponciano, C.R. \& Prioli, R. (2004). Metal layer mask patterning by force microscopy lithography. Material Science and Engineering B., 112, 194.

Garcia, R.; Martinez R.V. \& Martinez, J. (2006). Nano-chemistry and scanning probe nanolithographies. Chem. Soc. Rev, 35, 29-38.

Geissler, M. \& Xia, Y. (2004). Patterning: Principles and Some New Development. Adv. Mater. 16, 1249-1269.

Heimberg, J. A. \& Zandbergen, H. W. (2004). Superlubricity of graphite. Physical Review Letters 92 (12), 126101 (1) -126101.

Heyde, M.; Rademann, K.; Cappella, B.; Guess, M.; Strum, H.; Spanegenberg, T. \& Niehus, H. (2001). Dynamic plowing nanolithography on polymethylmethacrylate using an atomic force microscope. Rev. Sci. Instrum. 72, 136-141.

Hu, S.; Hamidi; A.; Altmeyer; S.; Koster, T.; Spangenberg, B. \& Kurz, H. (1998). Fabrication of silicon and metal nanowires and dots using mechanical atomic force lithography. J. Vac. Sci. Technol. B16, 2822-2824.

Huang, Y.; Duan, X.; Wie, Q. \& Lieber, C. M. (2001). Directed assembly of one-dimensional nanostructures into functional networks. Science, 291, 630-633.

Hues, S. M.; Draper, C. F. \& Colton, R.J., (1994). Measurement of Nanomechanical Properties of Metals Using the Atomic-Force Microscope. J. of Vacuum Science Technology, B12, 2211-2214.

Hyon, C. K.; Choi, S. C.; Hwang, S.W.; Ahn, D.; Kim, Y. \& Kim, E. K. (1999). Direct nanometer scale patterning by the cantilever oscillation of an atomic force microscope. Appl. Phys. Lett., Vol. 75, No. 2, 292-294.

Irmer, B.; Kehrle, M.; Lorenze, H. \& Kothaus, J. P.,(1998). Nanolithography by non-contact AFM-induced local oxidation: fabrication of tunnelling barriers suitable for singleelectron devices, Semicond. Sci. Technol., 13, A79-A82 . 
Iwanaga, Sh. \& Darling, R.B. (2005). Stable and erasable patterning of vanadium pentoxide thin films by atomic force microscope nanolithography. Applied Physics Letters, Vol. 86, 133113-133113-2.

Jones, A. G.; Balocco, C.; King, R. \& Song, A. M. (2006). Highly tunable, high-throughput nanolithography based on strained regionregular conducting polymer films. Appl. Phys. Lett. 89, 013119 (1-3).

Lee, H. T.; Oh, J. S.; Park, S. J.; Park, K. H.; Ha, J. S.; Yoo, H. J. \& Koo, J. Y. (1997). Nanometer-scale lithography on H-passivated $\mathrm{Si}(100)$ with an atomic force microscope in air. Journal of Vacuum Science Technology, A15(3), 1451.

Lemeshko S.; Saunin S. \& Shevyakov V. (2005). Atomic Force Microscope As a Tool for Nanometer Scale Surface Surface Patterning. Nanotechnology, 2, 719-721.

Li, S. F. Y.; Ng, H. T.; Zhang, P. C.; Ho, P. K. H.; Zhou, L.; Bao, G. W. \& Chan, S. L. H. (1997). Submicrometer lithography of a silicon substrate by machining of photoresist using atomic force microscopy followed by wet chemical etching. Nanolithography, 8, 76-81.

Lyuksyutov, S. F.; Paramonov, P.B.; Dolog, I. \& Ralich, R.M. (2003). Peculiarities of an anomalous electronic current during atomic force microscopy assisted nanolithography on n-type silicon. Nanotechnology, 14, 716-721 .

Lyuksyutov, S. F.; Paramonov, P. B.; Sharipov, R. A. \& Sigalov, G. (2004). Induced nanoscale deformation in polymers using atomic force microscopy. Physical Review B, 70, 174110-174110(1-8).

Magno, R. \& Bennett, B. R. (1997). Nanostructure patterns written in III -V semiconductors by an atomic force microscope. Appl. Phys. Lett. 70, 1855-1857.

Martin, C.; Rius, G.; Borrise, X. \& Perez-Murano, F. (2005). Nanolithography on thin layers of PMMA using atomic force microscopy. Nanotechnology, Vol. 16, pp.1016-1022.

Notargiacomo, A.; Foglietti, V.; Cianci, E.; Capellini, G.; Adami, M.; Faraci, P.; Evangelisti, F. \& Nicolini, C. (1999) Atomic Force Microscopy Lithography Study towards the Development of Nanodevices. Nanotechnology, 10, 458-463.

Park, J. \& Lee, H.,(2004). Effect of surface functional groups on nanostructure fabrication using AFM lithography. Material Science and Engineering C. 24, No.1, 311-314.

Quate, C. F. (1997). Scanning probe as a lithography tool for nanostructures, surface science. 386, 259-264.

Sadegh Hassani, S. \& Ebrahimpoor Ziaie, E. (2006). Application of Atomic Force Microscopy for the study of friction properties of surfaces. material science: $A n$ Indian journal, 2(4-5), 134-141.

Sadegh Hassani, S. \& Sobat, Z. (2011). Studying of various nanolithography methods by using Scanning Probe Microscope. Int .J. Nano .Dim 1(3), Winter 159-175.

Sadegh Hassani, S.; Sobat, Z. \& Aghabozorg, H. R. (2010). Force nanolithography on various surfaces by atomic force microscope. Int. J. Nanomanufacturing, Vol. 5, Nos. $3 / 4,217-224$.

Sadegh Hassani, S.; Sobat, Z. \& Aghabozorg, H. R. (2008a). Nanometer-Scale Patterning on PMMA Resist by Force Microscopy Lithography. Iran. J. Chem. Chem. Eng. Vol. 27, No. 4, 29-34.

Sadegh Hassani, S.; Sobat, Z. \& Aghabozorg, H. R. (2008b). Scanning probe lithography as a tool for studying of various surfaces. Nano Science and Nano Technology: An Indian journal, Volume 2 Issue (2-3),94-98. 
Samori, D. (2005). Exploring supramolecular interactions and architectures by Scanning Force Microscopies. Chem. Soc. Rev., 34, 551-561.

Santinacci, L., Djenizian, T., Hildebrand, H., Ecoffey, S., Mokdad, H., Campanella, T. \& Schmuki, P.,(2003). Selective Pd electrochemical deposition onto AFM-scratched silicon surfaces. Electro chimica Acta, 48, 3123-3130.

Santinacci, L.; Zhang, Y. \& Schmuki, P. (2005). AFM scratching and metal deposition through insulating layers on silicon. Surface Science, 597(1-3), 11-19.

Sheehan, P. E. \& Whitman, L. (2002). Thiol Diffusion and the Role of Humidity in Dip Pen Nanolithography. J. Physical Review Letters, 88, (156104-1)-(156104-4) .

Sheglov, D. V.; Latyshev, A. V. \& Aseev, A. L. (2005). The deepness enhancing of an AFMtip induced surface nanomodification. Applied Surface Science, 243(1-4), 138-142 .

Snow, E. S.; Campbell P.M. \& Perkin F. K. (1999). High speed patterning of a metal silicide using scanned probe lithography. Appl. Phys. Lett. 75(101476-1478..

Sumomogi, T.; Endo, T.; Kuwahara, K. \& Kaneko. R. (1995). Nanoscale layer removal of metal surfaces by scanning probe microscope scratching. J. Vac. Sci. Technol. B13, 1257-1260.

Sugimura, H.; Uchida, T.; Kitamura, N. \& Masuhara, H.,(1993). Tip- induced anodization of titanium surfaces by scanning tunneling microscopy: a humidity effect of nanolithography. Appl. Phys. Lett., 63, 1288.

Sugimura, H. \& Nakagiri, N. (1997). AFM lithography in constant current mode, Nanotechnology, 8 A15-A18.

Sundararajan S. \& Bhushan B. (1998). Micro/Nanotribological Studies of Polysilicon and SiC Films for MEMS Applications, Wear 217, 251-261.

Sundararajan, S. \& Bhushan, B. (2000). Topography-Induced Contributions to Friction Forces Measured Using an Atomic Force/Friction Force Microscope. Journal of Applied Physics, 88(8), 4825.

Vanlandingham, M. R. (1997). The effect of instrumental uncertainties on AFM indentation measurements. Microscopy Today 97 (10) 12-15.

Wendel, M., Kuhn, S., Lorenz, H., Kotthaus, J. P. \& Holland, M. (1994). Nanolithography with an Atomic Force Microscope for Integrated Fabrication of Quantum Electronic Devices. Appl. Phys. Lett. 65, 1775-1777.

Wendel, M.; Irmer, N.; Cortes, J.; Kaiser, R.; Lorenz, H.; Kotthaus, J. P. \& Lorke, A. (1996), Nanolithography with an Atomic Force Microscope. Superlattices and Microstructures 20 (3), 349-356.

Wendel, M.; Lorenz, H. \& Kotthaus. J. P. (1995). Sharpened electron beam deposited tips for high resolution atomic force microscope lithography and imagine. Appl. Phys. Lett. $67,3732-3734$.

Wilder, K. \& Quate, C. F. (1998). Noncontact nanolithography using the atomic force microscope Appl. Phys. Lett., 73 (17) 2527-2529.

Yasin, Sh.; Khalid, M. N.; Hasko, D.G. \& Sarfraz, S. (2005). Correlation of surface roughness with edge roughness in PMMA resist. Microelectronic Engineering, 78-79, 484-489.

Yeung, K. L. N. \& Yao, J.(2004). Scanning probe microscopy in catalysis. Nanosci. Nanotechol., $4,1-44$.

Yoshimura, T.; Shiraishi H.; Yamamoto J. \& Okazaki Sh. (1993). Nano edge roughness in polymer resist patterns. Appl. Phys. Lett. 63,(6), 764-766. 


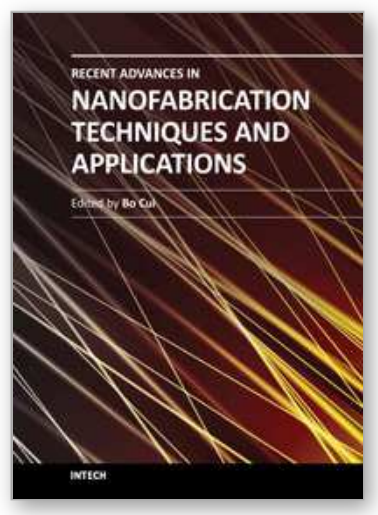

\author{
Recent Advances in Nanofabrication Techniques and Applications \\ Edited by Prof. Bo Cui
}

ISBN 978-953-307-602-7

Hard cover, 614 pages

Publisher InTech

Published online 02, December, 2011

Published in print edition December, 2011

Nanotechnology has experienced a rapid growth in the past decade, largely owing to the rapid advances in nanofabrication techniques employed to fabricate nano-devices. Nanofabrication can be divided into two categories: "bottom up" approach using chemical synthesis or self assembly, and "top down" approach using nanolithography, thin film deposition and etching techniques. Both topics are covered, though with a focus on the second category. This book contains twenty nine chapters and aims to provide the fundamentals and recent advances of nanofabrication techniques, as well as its device applications. Most chapters focus on indepth studies of a particular research field, and are thus targeted for researchers, though some chapters focus on the basics of lithographic techniques accessible for upper year undergraduate students. Divided into five parts, this book covers electron beam, focused ion beam, nanoimprint, deep and extreme UV, X-ray, scanning probe, interference, two-photon, and nanosphere lithography.

\title{
How to reference
}

In order to correctly reference this scholarly work, feel free to copy and paste the following:

S. Sadegh Hassani and H. R. Aghabozorg (2011). Nanolithography Study Using Scanning Probe Microscope, Recent Advances in Nanofabrication Techniques and Applications, Prof. Bo Cui (Ed.), ISBN: 978-953-307-6027, InTech, Available from: http://www.intechopen.com/books/recent-advances-in-nanofabrication-techniquesand-applications/nanolithography-study-using-scanning-probe-microscope

\section{INTECH}

open science | open minds

\section{InTech Europe}

University Campus STeP Ri

Slavka Krautzeka 83/A

51000 Rijeka, Croatia

Phone: +385 (51) 770447

Fax: +385 (51) 686166

www.intechopen.com

\section{InTech China}

Unit 405, Office Block, Hotel Equatorial Shanghai

No.65, Yan An Road (West), Shanghai, 200040, China

中国上海市延安西路65号上海国际贵都大饭店办公楼405单元

Phone: +86-21-62489820

Fax: $+86-21-62489821$ 
(C) 2011 The Author(s). Licensee IntechOpen. This is an open access article distributed under the terms of the Creative Commons Attribution 3.0 License, which permits unrestricted use, distribution, and reproduction in any medium, provided the original work is properly cited. 